\title{
AGRONEGÓCIO EM MOÇAMBIQUE: UMA BREVE ANÁLISE DA SITUAÇÃO DE ESTRANGERIZAÇÃO DO AGRONEGÓCIO
}

\author{
Nelson Maria Rosário ${ }^{1}$
}

\section{Resumo}

Moçambique possui um elevado potencial agrícola, as condições agroclimáticas são ideais, com 36 milhões de hectares de terra arável, clima tropical e subtropical com solos férteis e precipitação abundante e os principais rios oferecem enorme potencial de irrigação. O setor agrícola é ainda dominado pelo subsetor familiar que representa cerca de $90 \%$ da área cultivada. Este subsetor está fortemente dependente de técnicas rudimentares e culturas onde a irrigação depende exclusivamente da chuva, resultando deste modo em baixos rendimentos. Hoje, muitas explorações de grande dimensão têm sido revitalizadas através de investimentos estrangeiros e através de companhias de empresas em joint-venture e não só. E um dos grandes exemplos sobre o investimento estrangeiro no agronegócio moçambicano é a expansão do agronegócio Brasileiro para Moçambique, expansão essa feita através do programa Prosavana. O Prosavana é uma iniciativa tripartida entre os governos de Moçambique, Brasil e Japão, que tem como finalidade desenvolver a agricultura ao longo do corredor de Nacala, abrangendo as províncias de Nampula, Niassa e Zambézia. O presente estudo faz uma breve análise da estrangerização do agronegócio em Moçambique, as limitações da modernização da agricultura de Moçambique e as contradições da influência brasileira sobre o projeto ProSavana.

Palavras Chaves: Moçambique, Agronegócios, estrangerização e Prosavana

\section{AGRIBUSINESS IN MOZAMBIQUE: A BRIEF ANALYSIS OF THE AGRIBUSINESS BOTTLENECK SITUATION}

\begin{abstract}
Mozambique has a high agricultural potential, agro-climatic conditions are ideal, with 36 million ha of arable land, tropical and subtropical climate with fertile soils and abundant precipitation, and the main rivers offer enormous irrigation potential. The agricultural sector is still dominated by the family subsector which accounts for about $90 \%$ of the area under cultivation. This subsector is heavily dependent on rudimentary techniques and crops where irrigation depends exclusively on rainfall, resulting in low yields. Today, many large holdings have been revitalized through foreign investment and through joint venture companies and beyond. And one of the great examples of foreign investment in Mozambican agribusiness is the expansion of Brazilian agribusiness to Mozambique, expansion through the Prosavana program. Prosavana is a tripartite initiative between
\end{abstract}

${ }^{1}$ Professor da Escola Superior de Negócios e Empreendedorismo de Chibuto (ESNEC/UEM) e Doutorando em Desenvolvimento Rural na Universidade Federal do Rio Grande do Sul. E-mail: nemaro17@gmail.com. 
the governments of Mozambique, Brazil and Japan, which aims to develop agriculture along the Nacala corridor, covering the provinces of Nampula, Niassa and Zambézia. Therefore, the present study makes a brief analysis of the agribusiness mismatch in Mozambique, the limitations of the modernization of agriculture in Mozambique and the contradictions of the Brazilian influence on the ProSavana project.

Key Words: Mozambique, Agribusiness, Estranging and Prosavana

\section{AGRONEGOCIOS EN MOZAMBIQUE: UN BREVE ANÁLISIS DE LA SITUACIÓN DE LA ESTRANIZACIÓN DEL AGRONEGOCIOS}

\section{Resumen}

Mozambique tiene un elevado potencial agrícola, las condiciones agroclimáticas son ideales, con 36 millones de hectáreas de tierra cultivable, clima tropical y subtropical con suelos fértiles y precipitación abundante y los principales ríos ofrecen un enorme potencial de riego. El sector agrícola sigue dominado por el subsector familiar que representa alrededor del 90\% del área cultivada. Este subsector está fuertemente dependiente de técnicas rudimentarias y cultivos donde la irrigación depende exclusivamente de la lluvia, resultando de este modo en bajos rendimientos. Hoy en día, muchas explotaciones de gran tamaño han sido revitalizadas a través de inversiones extranjeras ya través de compañías de empresas en joint-venture y no sólo. Y uno de los grandes ejemplos sobre la inversión extranjera en el agronegocio mozambiqueño es la expansión del agronegocio brasileño a Mozambique, expansión que se hace a través del programa Prosavana. Prosavana es una iniciativa tripartita entre los gobiernos de Mozambique, Brasil y Japón, que tiene como finalidad de desarrollar la agricultura a lo largo del corredor de Nacala, abarcando las provincias de Nampula, Niassa y Zambézia. Por lo tanto, el presente estudio hace un breve análisis de la estranización de los agronegocios en Mozambique, las limitaciones de la modernización de la agricultura de Mozambique y las contradicciones de la influencia brasileña sobre el proyecto ProSavana.

Palabras claves: Mozambique, Agronegocios, estranización y Prosavana

\section{INTRODUÇÃO}

Moçambique é um país africano que se localiza na costa Sudeste da África, na zona austral do continente. O país está situado entre os paralelos $10^{\circ}-27^{\prime}$ e $26^{\circ}-52^{\prime}$ de latitude sul e entre os meridianos $30^{\circ}-12^{\prime}$ e $40^{\circ}-51^{\prime}$ de longitude este. O seu clima é, em geral, tropical e úmido. O país 
possui uma área aproximada de $799.380 \mathrm{Km} 2$ e tem as seguintes fronteiras: a norte com a República da Tanzânia, a noroeste com o Malawi e a Zâmbia, a oeste com o Zimbabwe e a República da África do Sul e a sul com a Suazilândia e também com a África do Sul. A este, numa extensão de 2.470 Km é totalmente banhado pelo Oceano Índico (DOS MUCHANGOS, 1999

Moçambique tem um elevado potencial agrícola, com uma área arável estimada de cerca de 36 milhões de hectares, dos quais apenas $10 \%$ são utilizados atualmente. A vasta diversidade de tipos de solos e condições climatéricas existentes no país tornam possível uma grande variedade de produções. A maioria da agricultura praticada no país é não-irrigada. Contudo, a rede de mais de 60 rios de Moçambique tem permitido a construção de pequenos esquemas de irrigação. O potencial total de área irrigável é de 3,3 milhões de hectares (Projeto agronegócio, 2014).

Nesse sentido, Moçambique com as condições que possue acaba por ser um país atraente para o investimento estrangeiro, razão pelo qual hoje existem vários países que investem no sector agrário Moçambicano. Sendo assim, o sector do agronegócio em Moçambique tem vivido tempos de elevado crescimento e grandes níveis de investimento. No entanto, existe ainda um grande caminho a percorrer, não só pela dimensão do território, mas também pela riqueza das suas terras e por este sector ser visto como vital para o desenvolvimento da economia Moçambicana.

Segundo Paiva (2013), em 2012, o mundo atingiu a marca de sete bilhões de habitantes. Seguiu-se à notícia um número infindável de artigos acerca de como alimentar toda esta população, cada dia mais urbanizada e com renda crescente. Em todos os debates, houve um ponto em comum: o papel do Brasil como detentor de tecnologia agrícola tropical e a África como nova fronteira agrícola.

O presente trabalho começa por trazer uma breve caracterização das potencialidades agícolas de Moçambique, sabido que o país possui abundantes recursos hídricos, terra arável e condições climáticas favoráveis, mas que, no entanto, essas condições não são integralmente aproveitadas para se alavancar a atividade agrícola e promoção do agro-negócios. De seguida, o estudo traz o ponto de situação atual do setor do agro-negócios em Moçambique que começa a dar os seus primeiros passos, isso pode-se explicar com a entrada do investimento externo, com destaque para o projeto Prosavana. E finalmente, o texto traz um olhar crítico da estrangerização desta atividade, trazendo exemplos de impactos gerados pelos projetos de agro-negócios no país. 


\title{
UMA BREVE DISCUSSÃO DOS CONCEITOS AGRONEGÓCIOS E PROCESSO DE ESTRANGERIZAÇÃO
}

O conceito de agronegócio teve sua origem na Universidade de Harvard e foi desenvolvido pelos pesquisadores John Davis e Ray Goldberg em 1957. Estes o definiram como resultado do processo que envolve as operações de produção e distribuição de suprimentos agrícolas, de produção nas unidades agrícolas, armazenamento, processamento, e distribuição dos produtos agrícolas e itens produzidos a partir deles. Os autores reconheceram que a agricultura não pode ser considerada isolada dos demais processos de fabricação de alimentos, sendo parte de uma grande rede de agentes econômicos, desde a produção de insumos até distribuição de produtos agrícolas (ZYLBERSZTAJN, 2005).

Há autores que abordam agronegócio como sinônimo de empresas transnacionais que controlam o mercado agrícola mundial, temos a contribuição de Stedile (2006, p. 17):

\begin{abstract}
Agronegócio é neoliberalismo da agricultura. Esse modelo neoliberal teve a sua amplitude também na agricultura. Selou-se uma aliança subordinada entre os grandes fazendeiros, os capitalistas, que se dedicam à exportação, com as empresas transnacionais que controlam o comércio agrícola internacional, as sementes, a produção de agrotóxicos e a agroindústria. O filhote desse matrimônio chamou-se agronegócio.
\end{abstract}

Para Fernandes (2010, p. 02), apesar de o termo agronegócio ser relativamente novo e utilizado para designar o modelo de desenvolvimento da agricultura capitalista, o seu modus operandi remonta às plantations do período colonial, passando por adaptações e modificações inerentes às diferentes etapas do modo capitalista de produção.

Mas ao contrário de significar apenas um termo para designar a agricultura capitalista, o autor afirma que o agronegócio é ainda,

[...] uma construção ideológica para tentar mudar a imagem latifundista da agricultura capitalista [...]. É uma tentativa de ocultar o caráter concentrador, predador, expropriatório e excludente para dar relevância somente ao caráter produtivista, destacando o aumento da produção, da riqueza e das novas tecnologias (FERNANDES, 2010, p.02).

Canuto (2004, p. 02-03) alinha na mesma vertente ao apontar que o agronegócio é apenas um novo nome para uma velha estrutura, buscando concretar a sua hegemonia no espaço agrário, uma vez que os avanços tecnológicos aplicados à produção agropecuária conseguiram ampliar as receitas econômicas graças ao incremento da produção e da produtividade. 
Já no que concerne ao processo de estrangerização, Borras e Franco (2010) usam o termo "land grabbing" ou apropriação de terras como um novo ciclo de desapropriação promovido pelo capital, onde se expõe cada vez mais a necessidade da governança da terra. Por outro lado, Fernandes (2011) utiliza o termo estrangeirização definindo este processo como uma nova característica da procura de novas áreas para a expansão da agricultura. $\mathrm{O}$ autor compreende que a estrangeirização está relacionada à crise de falta de alimentos e com o aumento do preço dos combustíveis.

Já a FAO (2011) utiliza os termos acaparamiento e "land grabbing" como aquisição de terras por governos estrangeiros (diretamente e não através de uma terceira empresa) em um país anfitrião, é apenas considerado acaparamiento ou "land grabbing" se as aquisições de terra ultrapassarem 1.000 hectares e investimentos que gerem de fato um impacto negativo sobre a segurança alimentar do país.

É importante referenciar que a estrangerização ocorre em todos os países do globo, estando mais concentrados o processo em países da América Latina e África Subsaariana (na qual Moçambique faz parte), pois apresentam baixo preço da terra, mão-de-obra barata e legislação ambiental e trabalhista maleáveis.

\section{CARACTERIZAÇÃO DAS POTENCIALIDADES AGRÍCOLAS DE MOÇAMBIQUE}

Moçambique possui um elevado potencial agrícola, com um clima predominantemente tropical, o país possui enormes extensões de terra arável para o desenvolvimento de actividades agro-pecuárias, a sua flora do tipo denso, aberto e savana, é extremamente rica em animais de grande, médio e pequeno porte, e de várias espécies de madeiras preciosas, algumas das quais bastante apreciadas no mercado internacional, alimentando, assim, a industria de exportação. O país é atravessado por vários rios de curso permanente, alguns dos quais nascem nos países vizinhos, além de possuir vários lagos e lagoas, o que faz com que os seus recursos hídricos sejam bastante invejáveis.

O MINAG (2013), agrupa o potencial que Moçambique possui para a atividade agrícola em quatro áreas chaves, a saber: A primeira área que é referente as condições agro-climáticas ideais. Aqui se destacam os 36 milhões de ha de terra arável, maioritariamente disponível para 
investimento; clima tropical e subtropical com solos férteis e precipitação abundante e os principais rios oferecem enorme potencial de irrigação. A segunda área diz respeito ao ambiente propício para o investimento. Nesta área destaca-se o investimento significativo pelo setor privado; previsão de mais de USD 14 bilhões e investimentos em infraestruturas até 2020 e várias parcerias públicoprivadas inovadoras. A terceira área é a das dinâmicas fortes de mercado. Aqui se destacam a economia forte; oportunidades para substituição de diversas importações agrícolas; oportunidades para produzir para exportações e localização costeira que tornam o acesso fácil aos mercados internacionais. E finalmente a quarta e última área correspondem ao comprometimento do governo ao crescimento do setor privado. Aqui o desenvolvimento agrário é visto como crucial para o desenvolvimento nacional; existência de programas governamentais de incentivos para empresas e instituições específicas criadas para auxiliar os investidores.

Portanto, apesar destas potencialidades acimas descrita, Moçambique continua a ser considerado um dos países mais pobre do mundo. Para a FIDA (2010), mesmo tendo Moçambique apresentado taxas elevadas de crescimento econômico, a pobreza continua a ser grave e generalizada. O número de moçambicanos que viviam na pobreza absoluta reduziu de $70 \%$, em 1997, para 54\%, em 2003, ano da última Pesquisa Nacional de Domicílios. Mesmo assim, a grande maioria da população rural ainda vive com menos de um dólar por dia e carece de serviços básicos, como o abastecimento de água potável e o acesso a serviços de saúde e escolas.

A pobreza ainda é um fenômeno predominantemente rural em Moçambique. A agricultura é a principal fonte de alimento e renda, mas a produtividade agrícola é muito baixa. Agricultores e pescadores geralmente produzem o suficiente para atender às necessidades básicas de alimento de suas famílias, tendo talvez um pequeno excedente para venda. A renda do cultivo e da pescaria é insuficiente e a maioria da população rural, que permanecem na sua maioria no nível da subsistência. As comunidades rurais são extremamente vulneráveis a desastres naturais como secas e enchentes, que ocorrem, particularmente, no Sul e no centro do país (FIDA,2010).

A baixa produtividade agrícola é resultado da falta de tecnologias e serviços de apoio apropriados. Também pode ser atribuída ao fato de que os mercados de produtos, além de distantes, 
não são confiáveis ${ }^{2}$ nem competitivos. Os pequenos agricultores dependem de métodos tradicionais de cultivo, variedades de sementes de baixo rendimento e técnicas de cultivo manual. São pouquíssimas as fontes alternativas de renda, o que aumenta a vulnerabilidade dos pobres rurais aos desastres naturais. Em tempos de escassez eles têm poucos recursos para protegê-los da insegurança alimentar. A produção agrícola moçambicana é realizada por dois setores: o empresarial e o familiar. A agricultura familiar em Moçambique constitui a actividade económica que ocupa grande parte da população, podendo alcançar mais de 75\% dos cidadãos (Mosca, 2014). Nas zonas rurais de Moçambique, a agricultura familiar é constituída essencialmente por pequenas explorações (aquelas que cultivam menos de 5 ha) 3 ; este sector concentra cerca de $99 \%$ das unidades agrícolas (3.090.197 unidades familiares) e ocupa mais de 95\% da área cultivada do país. As médias explorações agro-pecuárias, são constituídas por 37.296 unidades; as grandes explorações agropecuárias são 429 e apenas representam 1\% do total das explorações agropecuárias no país. A população vive principalmente de actividades agro-silvo-pecuárias de pequena escala, com uma heterogeneidade de actividades económicas de geração de rendimentos dentro das famílias. Dentro das diferentes actividades a produção de alimentos para o consumo constitui a base principal da estrutura produtiva do sector familiar (Sitoe, 2005, p. 4). Deve-se ainda resaltar que por ser uma agricultura de subsistência, ela depende principalmente das chuvas.

Por sua vez o setor empresarial começa-se a consolidar no país devido a entrada do investimento estrangeiro e de criação de diversos programas de incentivo a modernização agrícola da década de 2000 a 2010, como são exemplos disso o PROAGRI (Programa Nacional de Desenvolvimento Agrário) e Revolução verde. Este setor, têm registado melhores desempenhos nos anos mais recentes, embora a produção continue abaixo do seu potencial. Algumas explorações de grande dimensão têm sido revitalizadas através de investimento estrangeiro e através de companhias de empresas em joint-ventures, particularmente no sector do algodão (embora muitas empresas estejam a promover esquemas out-grower envolvendo pequenos agricultores). Desta forma, o sector

\footnotetext{
2 - As difíceis comunicações e os escassos meios de transporte, os diferentes tipos de produtores e de consumidores com lógica e racionalidades diversas geram mercados específicos, bastantes delimitados espacial e socialmente. Há funcionalidade entre estes mercados que nem sempre estão comunicados entre si, não so físicamente como em termos de conhecimento e acessibilidade dos atores econômicos, são essas algumas razões que explicam o fenómeno.
} 
empresarial nacional nas suas diferentes dimensões, tem gradualmente estado a conquistar o espaço no mercado regional internacional.

As províncias do centro e norte têm maior potencial agrícola que outras áreas do país, solos mais férteis, chuvas abundantes e geralmente produzem excedentes agrícolas. No sul do país o clima é mais seco, o solo é ruim e desastres naturais como enchentes e secas são ocorrências periódicas. Junto com as comunidades costeiras que sofrem de isolamento extremo, essas são as áreas mais pobres do país. Segundo o MINAG (2013), o setor agrícola contribuiu em 2012 com $25 \%$ do Produto Interno Bruto e $80 \%$ da massa laboral.

É importante que se realce que em Moçambique a maior percentagem da população vive na zona rural. SOUZA (2013), diz que 70\% dedica-se exclusivamente à agricultura familiar caracterizada por pequenas propriedades que cultivam menos de 5 ha. Este setor detém cerca $99 \%$ das unidades agrícolas e ocupam entre 90\% a 95\% de toda área cultivada do país. Em 2005 estas propriedades totalizavam 3.090.197 unidades, as médias e grandes propriedades, por sua vez, totalizavam 37.296 e 429 unidades respectivamente.

Entretanto, apesar apesar dos dados trazidos por Souza (2013), deve-se salientar que o valor das exportações dos produtos agrários mais importantes aumentou significativamente nos últimos anos, com destaque para tabaco, bananas, madeira e açúcar (Gráfico 1).

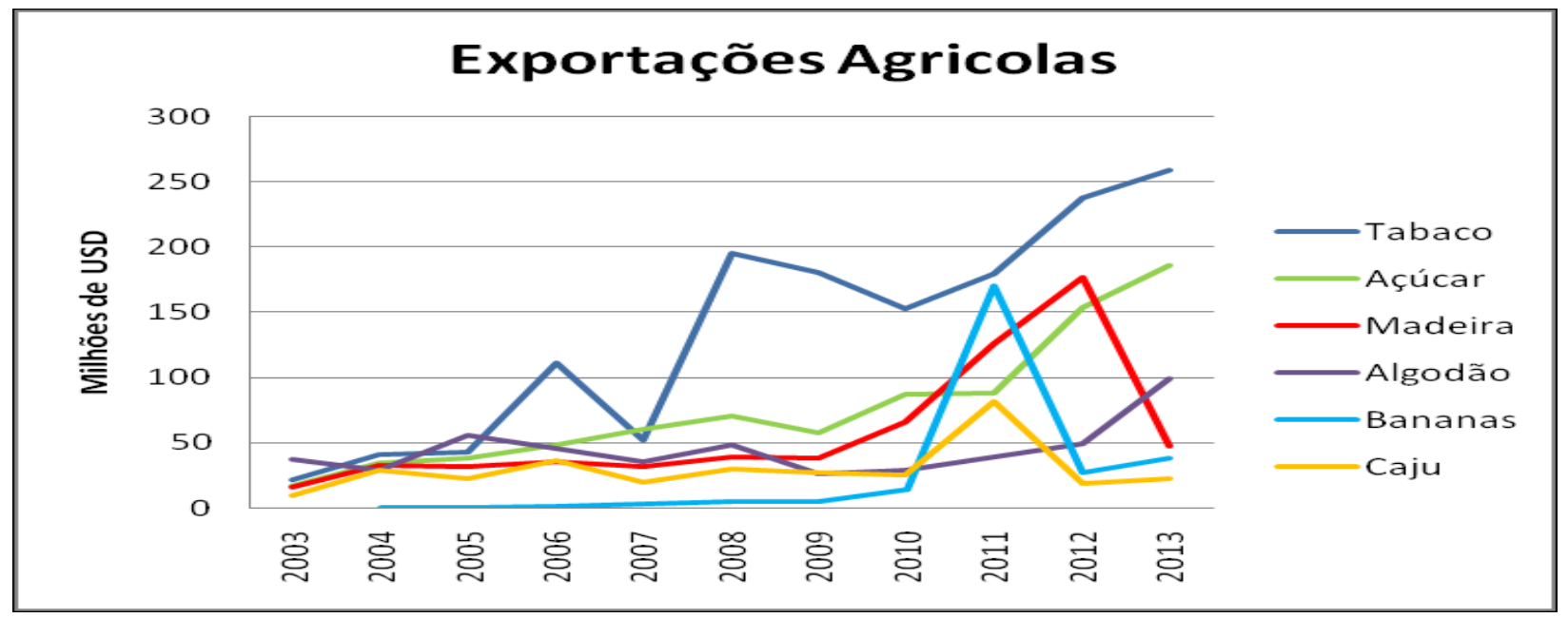

Fonte: Ministério da Agricultura (MINAG), 2013.

Segundo Mosca (2014), os sistemas de produção "tradicionais" sofreram, ao longo de décadas, diferentes níveis de transformação em consequência da intensidade de penetração do 
capital no meio rural, sobretudo o agrário e o comercial e o da extracção de recurso naturais. A urbanização, motivada por diferentes razões, económicas e não-económicas, tem provocado êxodos de diferentes dimensões sem serem acompanhados das transformações estruturais que permitam o aumento da produção e produtividade, para suprir a demanda de alimentos das cidades, o que é agravado por taxas de crescimento populacional, geralmente elevadas. Não só não houve mudanças estruturais na agricultura, como não houve um processo de industrialização que gerasse emprego para absorção do aumento demográfico. Em consequência, desenvolve-se uma economia informal, primeiro nas cidades e depois no campo.

Portanto, olhando para a fala de Mosca, fica claro que se apostando no fomento do Agronegócio, facilmente haverá o aumento da produção e produtividade agrícola, criando-se deste modo um elevado potencial de redução de pobreza em Moçambique.

\section{CARACTERIZAÇÃO DA SITUAÇÃO ATUAL DO SETOR DO AGRONEGÓCIOS EM MOÇAMBIQUE (ESTRANGERIZAÇÃO DO AGRONEGÓCIOS)}

O setor agrícola é ainda dominado pelo subsetor familiar que representa cerca de $90 \%$ da área cultivada. Este subsetor está fortemente dependente de técnicas rudimentares e culturas onde a irrigação depende exclusivamente da chuva, resultando deste modo em baixos rendimentos. A restante área arável é cultivada por grandes explorações comerciais que se dedicam exclusivamente em culturas de comercialização e de exportação.

Algumas explorações de grande dimensão têm sido revitalizadas através de investimentos estrangeiros e através de companhias de empresas em joint-venture, particularmente no setor do algodão (embora muitas empresas estejam a promover esquemas aut-grower envolvendo pequenos agricultores).

Portanto, importa salientar que novos sectores agrícolas de alto valor acrescentado estão a surgir em Moçambique. Segundo o Projeto Agronegócios (2014), o tabaco está a surgir como o setor cada vez mais importante, tendo crescido $+/-340 \%$ entre 2007 e 2012, setor dominado pela maior pela maior empresa agrícola moçambicana (nona maior do país em volumes de negócios e segunda empregadora), a Mozambique Leaf Tobacco, Lda, subsidiária da norte-americana Universal Corporation. Moçambique foi considerado o quarto maior produtor africano de tabaco em 
2010. As exportações atingiram o valor de 226 milhões de dólares em 2011, ultrapassando o algodão e o açucar, tendo se tornado no maior produto agrícola de exportação.

Em Moçambique existem condições propícias para o desenvolvimento da pecuária. A produção de gado bo vino, suino, caprino, de coelhos e aves apresenta um grande potencial, sendo que a oferta atualmente existente não satisfaz a procura doméstica. É por causa desse fato, que volumes significativos de carne, aves e produtos lácteos são importados, sobretudo da vizinha África do Sul, da Europa e do Brasil.

O Projeto Agronegocios (2014) diz que a partir do ano 2005, altura em que cerca de dois terços de frangos consumidos no país eram importados, uma nova iniciativa da Techno Serve (USAID) reuniu parceiros privados e o setor público numa tentativa de revitalizar a indústria. Hoje, cerca de $85 \%$ dos frangos consumidos no país são produzidos localmente. Existem hoje várias incubadoras que produzem pintos dayold, onde destaca-se a Higest, uma subsidiária do grupo portugês Higest Holding Lda.

Segundo Vunjanhe e Adriano (2015), 18 empresas assinara “cartas de intenções" detalhando suas intenções de investimento em Moçambique sob a Nova Aliança para a Segurança Alimentar e Nutricional $^{3}$, sete têm registo nacional e concessões de terra de mais de 20.000 hectares por 50 anos passíveis de renovação, cuja principais culturas são a soja, algodão e milho, todas voltadas para a exportação. Com a entrada das restantes 11 empresas multinacionais há um potencial de usurpação de mais de 300.000 hectares de terra só nos próximos 5 anos, tendo em conta os dados colhidos das intenções de projetos de investimentos manifestadas por estas empresas, ocupando as principais regiões agroecológicas dos corredores da Beira, Nacala e no vale do rio zambeze. Dessas 11 empresas, destacam-se a Reio do Agro e MOZACO (tabela 1).

\footnotetext{
${ }^{3}$ É uma iniciativa que resulta de um acordo assinado por cerca de 40 estados e instituições financeiras e organizações multilaterais internacionais em 2009 na cimeira do G8 de L'Aquila, Itália, depois de ter sido apresentada pela primeira vez pelo Governo dos Estados Unidos da América, sob a liderança do Presidente Barack Obama. Com esta iniciativa, o G8 argumenta que pretende cooperar com os Governos africanos para libertar 50 milhões de africanos da pobreza, 3.1 milhões dos quais em Moçambique entre 2012 e 2022. Com o referido acordo foi ainda estabelecido um suposto Programa Mundial para Agricultura e Segurança Alimentar do Banco Mundial estimado em US\$ 20 mil milhões. Seis países africanos, dos 20 previstos, já aderiram a Nova Aliança: Burquina Faso, Costa do Marfim, Etiópia, Ghana, Moçambique e Tanzânia.
} 
Tabela 1: Empresas Estrangeiras operando no setor do agronegócio Moçambicano.

\begin{tabular}{|l|l|l|l|}
\hline Nome da Empresa & Produção/Cultura & Localização & Área de concessão \\
\hline Rei do Agro & & & \\
\hline MOZACO $^{5}$ & Soja & Gojaé-Zambézia & 10.000 hectares \\
\hline
\end{tabular}

Fonte: Adapitado pelo autor a partir de Vunjanhe e Adriano (2015).

Um outro exemplo sobre a estrangerização do agronegócio no país é a expansão do agronegócio Brasileiro para Moçambique, expansão essa feita através do programa PROSAVANA. O Prosavana é uma iniciativa tripartida entre os governos de Moçambique, Brasil e Japão, que tem como finalidade de desenvolver a agricultura ao longo do corredor de Nacala, abrangendo as províncias de Nampula, Niassa e Zambézia. O prosavana é inspirado no programa de desenvolvimento do cerrado Brasileiro (PROCEDER), inicialmente apresentado como sua réplica (Figura 1).

Segundo Panquene (2013), o Prosavana vai ocupar 6 milhões de hactares de terra, uma parte considerável da terra agricultável do país, num contrato de 50 anos renováveis, ao preço de noves euros anuais por hectare. As empresas brasileiras do agronegócio irão produzir commodities que serão exportados para o Japão, serão produzidos principalmente a soja, o algodão e milho.

\footnotetext{
${ }^{4}$ Recebeu da USAID 750.000 USD com vista ao desenvolvimento de seus sistemas de irrigação e incrimento da sua produção de soja que é exportada para o mercado Europeu e asiático. Rei do Agro é uma empresa de capitais norteamericanos, pertencente a Aslan Group.

${ }^{5}$ Mozambique Agricultural Corporation (MOZACO), foi criada em 2012 numa joint venture entre a Rio Forte (Parte do grupo Espírito Santo de Portugal) e o grupo moçambicano de origem portuguesa João Ferreira dos Santos (JFS).
} 
Figura 1: Prosavana - Moçambique e Proceder - Brasil

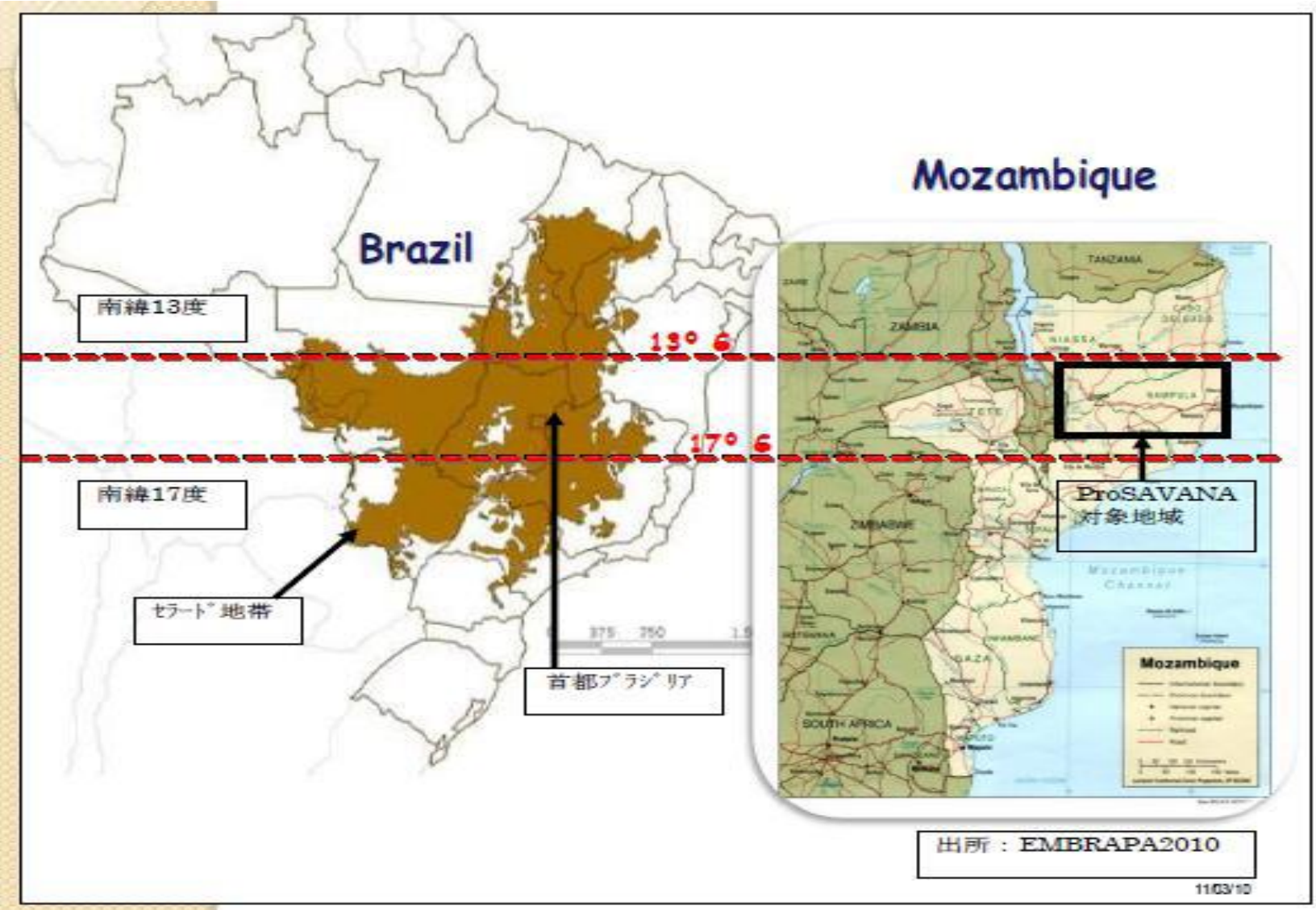

Fonte: Apresentação PPT feita pelo MINAG, durante a Conferência Triangular dos Povos, realizada em Maputo, no dia 08 de Agosto de $2013^{6}$.

\section{UM BREVE OLHAR CRÍTICO DA ESTRANGERIZAÇÃO DO AGRONEGÓCIOS EM MOÇAMBIQUE: O CASO PROSAVANA}

\footnotetext{
${ }^{6}$ Detalhes adicionais sobre a conferência triangular dos povos acesse: http://www.unac.org.mz/index.php/7-blog/56povos-de-mocambique-brasil-e-japao-discutem-em-maputo-formas-de-resistencia-detencao-e-reflexao-do-prosavana acessado em 06 de Novembro de 2016.
} 
Historicamente, o agronegócio requereu vastas extensões de terra e uso de tecnologias avançadas, incluindo agrotóxicos que comprometeram a fertilidade do solo em partes do mundo onde este modelo foi largamente desenvolvido.

O continente Africano é atrativo no que diz respeito a expansão do agronegócio não só pelas terras férteis, mas principalmente pela sua situação de fragilidade política e vulnerabilidade decorrente da extrema pobreza. É o caso de Moçambique, país com o terceiro pior IDH do mundo no último relatório das Nações Unidas.

Para Vunjanhe e Adriano (2015), O Prosavana é considerado um dos maiores negócios de terra do século XXI sem precedentes, protagonizado por Governos brasileiro e japonês no continente africano, sem o mínimo de transparência e, sobretudo, com impactos extremamente prejudiciais para milhões e milhões de comunidades e famílias moçambicanas de camponeses e camponesas.

Carlos Ernesto Augustin ${ }^{7}$, revela de uma forma tão objectiva e directa a verdadeira razão que move a agenda do Brasil em África. Em entrevista à Folha de S. Paulo afirmou": "Moçambique é um Mato Grosso no meio da África, com terra de graça, sem tanto impedimento ambiental e frete muito mais barato para a China." Em outro desenvolvimento afirma, "Hoje, além da terra ser caríssima em Mato Grosso, é impossível obter licença de desmate e limpeza de área. " Finalizando o seu discurso com uma declaração no mínimo preocupante. "Quem vai tomar conta da África? Chinês, europeu ou americano? O brasileiro, que tem conhecimento do cerrado". Fato curioso é ser o próprio Brasil que, sistematicamente, acusa países ricos de prejudicarem os emergentes com políticas "injustas", a levar para a África projetos insustentáveis. Em várias ocasiões, inclusive em fóruns da ONU, o Brasil tem dito ser vítima de políticas desleais de países do "primeiro mundo". É caso para dizer "não faça aos outros o que não gostaria que fizessem a você".

Quanto a insustentabilidade dos pojetos existentes em Moçambique, deve antes dizer que os megaprojetos são vistos como sendo a esperança para o desenvolvimento econômico e social do país. No entanto quando se olha a realidade vê- se que estes só servem para explorar a riqueza natural

\footnotetext{
${ }^{7}$ Presidente da Associação Mato-Grossense dos Produtores de Algodão

${ }^{8}$ Noticia disponível em http://www1.folha.uol.com.br/fsp/mercado/me1408201102.htm.Acesso em 07 de Novembrol de 2016
}

Sociedade e Território - Natal. Vol. 31, N. 1, p. 183-200

195

Jan./Jun. de 2019 / ISSN:2177-8396 
e enviá-la para o exterior. Vários fatores obscuros confirmam essa conclusão, um deles é a pouca informação disponibilizada acerca destes megaprojetos. Muito dos contratos assinados entre o governo e as multinacionais são mantidos em sigilo, nem mesmo as instituições de pesquisa tem acesso a tais contratos. De acordo com Castel-Branco (2002) os megaprojetos têm enorme contribuição nas exportações e substanciais ganhos líquidos de comércio, mas pecam por estarem concentrados em produtos primários, tão poucos que a economia moçambicana continuará sendo muito vulnerável a pequenas flutuações no mercado mundial para os produtos primários exportados. Além disso, os megaprojetos não substituem importações e, num certo sentido, aumentam a dependência do investimento relativamente a importações. Castel-Branco (2002) destaca ainda que poucas pequenas e médias empresas conseguiram se associar ao capital internacional e participar como fornecedoras. Elas não conseguem se desenvolver em todos os sentidos como: expansão, modernização e especialização, formação de parcerias, substituição de importações, exportação, etc. Castel-Branco (2009) afirmou que a riqueza gerada pelos megaprojetos.

De acordo com Mucanze (2016), esses grandes fluxos de Investimento Estrangeiro encontram em Moçambique um ambiente institucional frágil. Por isso conseguem contratos com grandes incentivos fiscais, encontram um conflito político entre o partido-Estado que está no poder há 4 décadas e um partido de oposição que possui a própria milícia armada. As transnacionais deparam-se também com uma grande liberdade pois o país não possui infraestruturas nem conhecimento técnico para auditar a atuação delas em Moçambique.

Entretanto, a União Nacional dos Camponeses de Moçambique (UNAC) veio a público lamentar a sua exclusão, arrogância por parte dos executores do projeto, e denunciam uma eminente usurpação de terras de famílias camponesas ao longo do corredor abrangido pelo ProSavana. O movimento campesino moçambicano, em seu site oficial, entre várias denúncias, diz que o megaprojeto é resultante de uma política do tipo "top-down".

Segundo Vunjanhe e Adriano (2015), O posicionamento da UNAC baseou-se na evidente contradição entre sistemas de produção camponeses quando comparados com os propositos do agronegócio, que representam uma proposta ostensiva e imperialista com vista a captura dos territórios e modos de vivência das comunidades do Corredor de Nacala. 
Recentemente, uma denúncia feita pela Acção Académica para o Desenvolvimento das Comunidades Rurais (ADECRU), revela que a Matharia Empreendimento, uma empresa financiada pelo Prosavana através do Fundo da Iniciativa de Desenvolvimento do ProSAVANA (ProSAVANA Development Initiative Fund - PDIF), usurpou terras de mais de 200 famílias camponesas no distrito de Ribaué, Posto Administrativo de Iapala, comunidade de Matharya para dar lugar a produção de soja. O PDIF inicialmente contou com um pacote de 750.000 \$US que vem do Fundo Contraparte (Mikaeri Shikin), que agrega fundos provenientes da assistência japonesa alimentar (KR), enquadrada na Ajuda Oficial ao Desenvolvimento (ODA). A denúncia afiança ainda que a população atingida pela empresa está, actualmente, a pedir terras ao proprietário da Mathatria Empreendimento para a produção de alimentos, isto porque para além da terra usurpada, já não há terras para eles produzirem nas áreas adjacentes. Estes factos revelam os temores do surgimento de comunidades sem terra avançado pela UNAC em 2012 e reafirmado na carta aberta e demais documentos de posição dos diferentes atores sociais, (Vunjanhe e Adriano, 2015, p.82-83).

Paiva (2013) afirma que desde seu lançamento, o ProSavana é acusado de tentar destruir a agricultura moçambicana por meio de uma "invasão de megaprodutores brasileiros", que "se utilizariam de financiamento japonês", em uma "repetição do processo que destruiu o Cerrado brasileiro". A outra crítica é o facto do ProSavana ser a repetição do Programa de Desenvolvimento do Cerrado, o Prodecer, realizado a partir do fim dos anos 70, levando a JICA a ser acusada de promover em Moçambique as mesmas práticas que promoveu no Brasil há mais de trinta anos. Há três décadas, a Eco 92 estava longe de ocorrer, e o governo brasileiro financiava desmatamentos nas propriedades rurais do Brasil.

Para Perin (2014) citando a Posição das ONGs Justiça Ambienta e FOE (Friends of Earth) Moçambique sobre o programa ProSavana (2013), refere que o programa Prosavana foi hábil e convenientemente embrulhado numa elegante linguagem "verde" e tem sido apresentado aos moçambicanos e à comunidade internacional como um programa de "desenvolvimento agrícola sustentável", deixando completamente de lado os potenciais impactos sociais e ambientais do mesmo. No entanto, num programa desta dimensão, em que se prevê ser necessário o reassentamento de comunidades, é preocupante perceber que estas pouco ou nada sabem do mesmo. 
É mais um programa desenhado e decidido ao mais elevado nível, sem qualquer envolvimento dos camponeses e comunidades locais, o dito público alvo.

Ainda Perin (2014) refere no seu artigo que a sociedade civil moçambicana receia que a implantação do ProSavana leve ao empobrecimento das comunidades rurais e redução de alternativas de sobrevivência, gerando um êxodo dessa população para as áreas urbanas. Teme-se ainda o agravamento da situação de insegurança alimentar e redução da qualidade de vida dos camponeses, em um quadro de perda progressiva de seus direitos consuetudinários sobre a terra, o aumento da corrupção e de conflitos de interesse. As preocupações se dão também em torno de questões ambientais, como a possibilidade de poluição de recursos hídricos, empobrecimento do solo a partir do uso excessivo de pesticidas e fertilizantes químicos, desmatamentos de extensas áreas para produção, consequente desequilíbrio ecológico e redução do bioma

\section{CONSIDERAÇÕES FINAIS}

Moçambique é um país com muitas potencialidades para o desenvolvimento da agricultura e consequentemente do agronegócio. São exemplos destas potencialidades as condições agroclimáticas ideiais, o ambiente propício para o investimento, as dinâmicas do mercado e o compromisso do governo no crescimento do setor privado. Apesar das potencialidades existentes, as mesmas não são exploradas na sua totalidade, o que faz com que a produção e produtividade continuem em níveis bastantes baixos e consequentemente o surgimento da insegurança alimentar.

Moçambique atraente devido as suas potencialidades, aliada a situação de pobreza extrema, o governo de Moçambique procura criar ambiente favorável ao investimento com o objectivo de reduzir ainda mais os índices de pobreza. E como resultado, hoje assiste-se em Moçambique ao aparecimento de instituições estrangeiras no desenvolvimento de atividades agrárias em Moçambique.

São exemplos da estrangerização das atividades agrárias em Moçambique, o programa ProSavana, Rei do agro que se didica na produção de soja, MOZACO, dedica-se na produção de soja, algodão e girassol e a Mozambique Leaf Tobacco, uma subsidiária da norte-americana 
Universal Corporation. O Prosavana é considerado um dos maiores negócios de terra do século XXI sem precedentes, protagonizado por Governos brasileiro e japonês no continente africano, sem o mínimo de transparência e, sobretudo, com impactos extremamente prejudiciais para milhões e milhões de comunidades e famílias moçambicanas de camponeses e camponesas.

\section{REFERÊNCIAS}

BORRAS, Saturnino Jun; FRANCO, Jennifer. Towards a Broader View of the Politics of Global Land Grab: rethinking land issues, reframing resistance. ICAS Working Paper Series, 2010.

CANUTO, Agronegócio: A modernização conservadora que gera a exclusão por produtividade. Revista Nera: Presidente Prudente, 2004. Disponível em http://revista.fct.unesp.br/index.php/nera/article/view/1466>. Acesso em 06 de Agosto de 2019.

CASTEL-BRANCO, C. N. Megaprojetos e estratégia de desenvolvimento: notas para um debate. Maputo: Instituto de Estudos Sociais e Econômicos, 2002. Disponível em:

http://www.iese.ac.mz/lib/cncb/Mega_projectos_Moz_texto.pdf . Acesso em: 10 de Agosto 2017.

FERNANDES, B. M, Agronegócio e a Reforma Agrária. Revista Nera. Presidente Prudente: UNESP,2010.Disponível.em..http://:www2.fct.unesp.br/nera/publicacoes/agronegocioereformaagr aria_Bernardo.pdf . Acesso em 07 Agosto. 2019.

FERDANDES, Bernardo Mançano. Estrangeirização de terras na nova conjuntura da questão agrária. Caderno de Conflitos no Campo de 2010, Comissão Pastoral da Terra: Goiânia, 2011.

FAO. El acaparamiento de tierras en América Latina y el Caribe visto desde una perspectiva internacional más amplia. Roma: FAO. 2011.

FIDA. Habilitar os pobres rurais a superar a pobreza em Moçambique, Itália, 2010.

MINAG. Estratégia do Governo e Oportunidades de Investimento no Agronegócios em Moçambique, Maputo, 2013. Disponível em http://fsg.afre.msu.edu/mozambique/caadp/Apresentacao_Nova_Alianca_Intro_CEPAGRI.pdf, acessado em 03 de Novembro de 2016.

MOSCA, João. Agricultura familiar em Moçambique: Ideologias e Políticas, CESA, Lisboa, 2014. Disponível em https://pascal.iseg.utl.pt/ cesa/files/Doc_trabalho/WP127.pdf, acessado em 01 de Novembro de 2016.

MUCANZE, Nelson A. Investimento Direto Estrangeiro em Moçambique: aspectos Positivos e Negativos, Dissertação, Araraquara, São Paulo, 2016. 
MUCHANGOS, Aniceto Dos. Moçambique: Paisagens e regiões naturais, Maputo, 1999

PAIVA, Frederico Dimas. Agricultura em Moçambique. PROSAVANA: críticas e esclarecimentos, 2013. Disponível em

http://bibliotecadigital.fgv.br/ojs/index.php/agroanalysis/article/viewFile/20067/18812, acessado em 07 de Novembro de 2016.

PERIN, Vanessa. O ProSavana: transferência de tecnologia agrícola para "repetir em Moçambique o que fizeram com o cerrado 30 anos atrás”, 2014. Disponível em

http://eventos.livera.com.br/trabalho/98-1020644_30_06_2015_21-36-14_6569.PDF. Acessado em 08 de Novembro de 2016.

PROJETO AGRONEGÓCIO. Agronegócio, Moçambique. Market Research e Intelligence, tecnologia e serviços de Agronegócios, Lisboa, 2014.

SITOE, Tomas A. Agricultura familiar em Moçambique. Estratégias de Desenvolvimento Sustentável, Maputo, 2005.

STEDILE, J. P. A sociedade deve decidir o modelo agrícola para o país. Revista Caros Amigos. São Paulo: Casa Amarela, ano 10, n.109, p. 17, abr. 2006.

SOUZA, J. Wilson N. De, et.all. Caracterização da Agricultura em Moçambique, 2013.

Disponível em http://agroluso.blogspot.com.br/2013/07/caracterizacao-da-agricultura-em.html, acessado em 03 de Novembro de 2016.

ZYLBERSZTAJN, D. NEVES, M. F. NEVES, E. M. Agronegócio no Brasil. Ed. Saraiva. São Paulo - SP, 2005.

VUNJANHE, Jeremias e ADRIANO, Vicente. Segurança Alimentar e Nutricional em Moçambique: um longo caminho por trilhar, CESESAN, UFRRJ, Rio de Janeiro, 2015.

Recebido em Janeiro de 2018

Aprovado em Fevereiro de 2019

Publicado em Agosto de 2019 